\title{
An Analysis of Utility and Effectiveness of Extension Methods Employed by the Extension Personnel of Public Extension System in Southern Tamil Nadu
}

\author{
N. Poovarasan ${ }^{1}$, M. Ramasubramanian ${ }^{2 *}$, M. Senthil Kumar ${ }^{3}$ and A. Anuratha ${ }^{4}$ \\ ${ }^{1}$ Departmentof Agricultural Extension and Rural Sociology, Agricultural College and \\ Research Institute, Madurai, India \\ ${ }^{2}$ Krishi Vigyan Kendra, Needamangalam, Thiruvarur District \\ ${ }^{3}$ Directorate of Extension Education, TNAU, Coimbatore, India \\ ${ }^{3}$ Soil Science, Krishi Vigyan Kendra, Needamangalam, Thiruvarur District, India \\ *Corresponding author
}

\begin{tabular}{|l|}
\hline K e y w o r d s \\
$\begin{array}{l}\text { Public extension } \\
\text { system, Extension } \\
\text { methods, Utility, } \\
\text { effectiveness }\end{array}$ \\
\hline Article Info \\
\hline $\begin{array}{l}\text { Accepted: } \\
\text { 12 November } 2020 \\
\text { Available Online: } \\
\text { 10 December } 2020\end{array}$ \\
\hline
\end{tabular}

\section{Introduction}

In India public extension is central in formulating and disseminating knowledge and in teaching farmers to be competent decision makers. From the Community Development Programme started in 1952 through the
A study was conducted among 75 Extension Officials of State Department of Agriculture in Theni District of Tamil Nadu to analyse the utility and Effectiveness of Extension Methods. The study revealed that among all the extension methods irrespective of the classification, Farm and home visit was frequently utilized by the extension officials ( 58 per cent).As far as group methods are concerned, meetings (100 per cent) and trainings (96 per cent) were found to be frequently utilized methods followed by tours ( 68 per cent) and demonstration (68 per cent). Leaflets ( 96 per cent), Folder ( 84 per cent) and Booklet were the frequently utilized extension literature which came under mass method. Mobile services were reported to be frequently utilized by majority ( 84 per cent) of extension officials. Majority of extension officials reported that they utilized sometimes participatory methods of Focus group discussion (76 per cent), Participatory workshop (64 per cent) and brainstorming (52 per cent). Meetings ( 72 per cent t \& 28 per cent), Demonstrations (68 per cent \& 24 per cent) and Trainings (56 per cent) and (44 per cent) were the group methods rated to be very effective to effective by extension officials with REI of 372,356 and 348 respectively. Variables namely Skill in choosing appropriate extension methods $\left(\mathrm{X}_{5}\right)$ and experience in employing extension methods $\left(\mathrm{X}_{7}\right)$ were found to be positive and significantly contributing towards the Relative Effectiveness of Extension methods in Public Extension system at five per cent level of probability. 
Visit system in a pilot basis in selected districts of some states. This was judged to be very successful. There after the process has been to increasingly widen the coverage of this project in to other states in the country. Although the $\mathrm{T} \& \mathrm{~V}$ system was, in its early years, a very appropriate approach to extension delivery, that focus was in food crops only, much more in irrigated areas than in non-irrigated areas. The approach was justified because our priority was to attain self-sufficiency in food grain production. It clicked, as it involved some simple extension messages revolving around fertilizers, varieties and water to show significant advances in productivity.

Until 1960's agricultural extension was purely a function performed under the guidance of State Department of Agriculture. In order to facilitate public extension, the Indian Council of Agricultural Research (ICAR) started getting involved in extension activities with the National Demonstration Programme in 1964. ICAR's involvement increased considerably with the initiation and spread of Krishi Vigyan Kendra's (KVK's). Some new programmes like Institutions Village Linkage Programme (IVLP), Agricultural Technology Information Center (ATIC) and Agricultural Technologies Management Agency (ATMA) are also undertaken for transfer of technology. Recently National Agricultural Innovation Programme (NAIP) National Agricultural Development Project (NADP) was introduced and they were in operation.

In India, as the public Extension by various states and Central Government Institutions is the predominant mode of technology transfer the approach and mode of technology transfer is pivotal for its effectiveness. Further, the competency of Extension personnel employed in Public Extension System play a major role in the success of any Extension programme. Hence, Singh et al., (2013) in their study indicated that there is a need for a thorough evaluation of extension approaches in order to identify best practices and to understand their impact on farming communities in reaching small-scale and marginal farmers. Kaur and Kaur (2018) were of the opinion that various extension approaches completed successfully by giving satisfactory results in past to improve the farmers knowledge regarding newly developed agricultural technologies. Some of them are continuously running in present along with newly developed extension approaches and requires little modifications in future to increase the agricultural potential of country. The use of innovative extension approaches to increase coverage is, therefore, a concern for all involved in agriculture extension and advisory services.

A study conducted by Khan and Akram (2012) ranked the extension methods undertaken by extension personnel which revealed that farm/home visit was perceived as very good and best method having rank ' 1 ', followed by field days at ' 2 ' and demonstration plots at ' 3 ' on the basis of their weighted score. Baral et al., (2018) in his study found that the group extension method was highly preferred by the farmers and it was found that the extension personnel contact under the project was satisfactory with methods like minikit, demonstrations and trainings having higher contact, thus helping in increasing social network of farmers.

Jonna (2012) found that the farmers preferred farmer-to-farmer as the most effective extension method of these three. The extension providers said that demonstrations is the most effective method. A crosssectional survey research was conducted by Hung (2018) to investigate the effectiveness of extension delivery methods used in the Central region of Vietnam and the study revealed that extension methods including 
training, farmer-to-farmer extension, farmers' group meetings, and farm/home visits were most effective. In contrast, extension methods including the use of radio programs, posters, and booklets were not effective

The literature provided related to studies undertaken on Extension approach, methods employed by Extension personnel revealed that there are dearth of literature on Effectiveness of Public Extension System in India. Further, limited studies were found to support the association of characters of Extension Personnel and the utility and effectiveness of Extension methods. In order to plug this research gap, the present study has been contemplated with the objective of analyzing the utility and effectiveness of Extension methods employed by Extension personnel of State Department of Agriculture in Tamil Nadu followed by assessing the contribution of profile of Extension personnel with Effectiveness of Extension methods.

\section{Materials and Methods}

In the present study, Ex-post-facto research design was used as the researcher instead of creating a treatment evaluates the effects of naturally occurring treatment, after it has occurred. Since the present investigation concerned with the effectiveness of different Extension Service Providers and the utility of different extension methods, wherein the effect has already occurred and the causes were traced.

The study was taken up in Tamil Nadu, wherein Theni district was selected purposively as the district is endowed with rich natural resources, majority of the area under cultivation is irrigated with diverse agricultural crops and horticultural crops. Further, the district is well served by both formal and informal extension system namely Department of agriculture, Horticulture and other line departments, KVK and plethora of NGOs. There were eight blocks in Theni district. Respondents for the study were selected from all the eight blocks namely Andipatti, Chinnamanur, K Myladumparai, Theni, Bodinayakkanur, Kambam Periyakulam and Utamapalayam. A total of 25 extension officials 3 each in each block including ADA, AO and AAOs were selected purposively for the study using deliberate sampling. Respondents of Department of Agriculture were contacted at JDA office, Theni and Block Extension Centers in respective blocks.

Two dependent variables were exclusively designed for this study. One is utility of Extension Methods and another one is Relative Effectiveness of Extension Methods. utility of Extension Methods refers to the extent to which the extension methods were employed by extension workers of public extension system for various extension activities. The scoring procedure was developed for the study wherein three point continuum was used namely frequent utility, sometimes and rarely which were assigned scores of 3,2,1 respectively. Utility Index(UMUI) was developed for each of the extension system and the formula is given below

$$
\text { Utility index }=\frac{(\mathrm{X} 1 \times 3)+(\mathrm{x} 2 \times 2)+(\mathrm{x} 3 \times 1)}{\text { Total number of respondents }}
$$

$\mathrm{X} 1=$ No.of extension workers frequently utilized selected extension methods

$\mathrm{X} 2=$ No.of extension workers who sometimes utilized selected extension methods

X3 $=$ No.of extension workers who utilized rarely the selected extension methods 
Similarly, is Relative Effectiveness of Extension Methods refers to the degree to which a particular extension method was rated to be effective by the extension officials working in Public extension system. The extension methods which were classified into Individual method, Group method, Mass methods, ICT tools for technology transfer, Participatory methods were given to the extension officials of Public extension system (respondents) in 4 point continuum namely Very effective, Effective, Moderately effective and Less effective which were given scores of 4,3,2 and 1 respectively

An index called Relative Effective Index (REI) was developed for the study to analyse the effectiveness of each of the extension methods in comparison to other methods. The formula for calculating REI is given below

Relative effective index $=\frac{(\mathrm{X} 1 \times 4)+(\mathrm{X} 2 \times 3)+(\mathrm{X} 3 \times 2)=(\mathrm{X} 4 \mathrm{X} 1)}{\text { Total number of respondents }} \times 100$

$\mathrm{X} 1$ = No of respondents rated the extension methods as very effective

$\mathrm{X} 2=$ No of respondents rated the extension methods as moderately effective

$\mathrm{X} 3$ = No of respondents rated the extension methods as effective

$\mathrm{X} 4=$ No of respondents rated the extension methods as not at all effective

The data collection was done with the use of a well - structured and pre-tested interview schedule. The data pertaining to the profile of the Extension officials of Department of Agriculture and two variables namely Utility Index and Relative Effectiveness Index were collected from the respondents. The profile of the respondents were taken as Independent variable and the Relative Effectiveness Index was taken as the Dependent Variable and
Multiple regression was run using SPSS 21.0 to find out the contribution of Independent variables on Dependent Variable.

\section{Results and Discussion}

The data pertaining to the hypothesized dependent and Independent variables were collected which were tabulated, analysed and the results are discussed in the succeeding pages.

Utility of extension methods by the Extension officials of Public Extension System

The extent of utility of various extension methods comprising of individual, Group, Mass contact methods besides ICT tools and participatory methods by the extension officials of Public extension system will give an idea about differential utility. The data pertaining to the utility of extension method by extension officials of Department of Agriculture is presented in table 1.

\section{Utility of individual methods}

Among all the extension methods irrespective of the classification, Farm and home visit was frequently utilized by the extension officials (58 per cent). The personal letter was found to be least utilized by extension officials as the utility index was lowest (36). Till today, Farm and home visit is the reliable individual extension method employed by extension officials. Though extension system has undergone different changes in Department of agriculture, this extension method was persistent due to its advantages. Since the mobile phones and communication gadgets came into the society in a bigger way, the personal letter was no longer believed to be an appropriate extension method. Hence it was not utilized. 


\section{Utility of group methods}

As far as group methods are concerned, meetings (100 per cent) and trainings (96 per cent) were found to be the frequently utilized methods followed by tours (68 per cent) and demonstration (68 per cent). Meetings and trainings were the most frequently conducted extension methods as they were part of several extension programmes like National Food Security Mission (NFSM), Agricultural Technology Management Agency (ATMA) etc., Demonstrations, Farmer field school, Field day were part of several state and centrally sponsored schemes IAMWARM, NFSM, ATMA and hence they were utilized sometimes by the extension officials. The utility index for group methods was in descending order of 300, 296, 268, $240 \& 224$ for Meetings, Trainings, Demonstrations, Tours, Farmer field school and Field day respectively.

\section{Utility of Mass methods}

Leaflets (96 per cent), Folder (84 per cent) and Booklet were the frequently utilized extension literature which came under mass method. An interesting observation here was that Radio (64 per cent) and Television (76 per cent) were reported to be 'rarely utilized' by the majority of extension officials. Keeping in view the enormous utility of Radio and Television for entertainment purpose, the extension officials seemed to have avoided the utility of them for transfer of technologies. There existed huge scope for improving this condition by tailoring the radio and Television programs in such a way that it attracts the farmers.

Majority of the extension officials reported to use 'sometimes' the mass extension methods namely Wall/tree posters (72 per cent), Hoardings/Flex boards (64 per cent). The extension officials have been using these methods when new schemes were introduced in the department. To create awareness, they were using these visual mass methods. The utility index for mass methods was in the descending order of 304, 296, 284, 204, 188, 180, 136,\& 124 for Booklets, Leaflets, Folders, Exhibition, Wall/tree posters, Hoardings, Radio and Television respectively.

Various schemes which were in operation in Department of agriculture warranted the extension officials to prepare Leaflets, Booklets, to create awareness about the schemes among the farmers. Hence extension officials were found to be frequently utilizing these extension literatures.

\section{Utility of ICT tools for technology transfer}

Among the ICT tools, Expert system (68 per cent), Portals (64 per cent), Social networks (64 per cent). Interactive CDs (60 per cent), were found to be utilized sometimes' by extension officials of Public extension system. Mobile services were reported to be frequently utilized by majority ( 84 per cent) of extension officials.

The ICT based extension methods which were rarely utilized by majority of extension officials were websites (84 per cent), e-mail (76 per cent), Video conferencing (60 per cent) and Teleconferencing (56 per cent).

The introduction of FCMS (Farm Crop Management System) in Department of Agriculture and their exposure to the portals like AGRISNET, TNAU agritech portal were the influencing factors for utility of factors. Through FCMS, SMS were being sent to large number of farmers besides attending queries raised by farmers through mobile phones. Hence the utility of mobile phones by extension officials has become the order of the day. Though the ICT tools permeated the extension officials of Public extension system 
they still have reluctance to use tools like Social networks and Video conferencing.

The utility index which was worked out for ICT based extension methods were in the descending order of 284, $244,188,180,168,148,144,132$ and 108 for Mobile services, Interactive CDs, Portals, Social networks, Expert system, Video conferencing, Tele conferencing, e-mail and websites respectively.

\section{Utility of Participatory extension methods}

Majority of extension officials reported that they utilized sometimes participatory methods of Focus group discussion (76 per cent), Participatory workshop (64 per cent) and brainstorming (52 per cent). These extension methods were used by extension workers for specific programmes which necessitated them to make farmers participate and eliciting information for writing reports. For example ATMA, NFSM etc., were the programmes needed cluster approach and hence extension officials were involved in participatory extension methods. The utility index worked out for three methods were 220,208,184 for Brainstroming, Focus group discussion and Participatory workshop respectively.

Relative effectiveness of extension methods as perceived by extension officials of Public Extension System

The main component of the present study was to assess the relative effectiveness of extension methods as perceived by extension officials of different organizations. In this line the relative effectiveness of extension methods as perceived by extension officials of Department of Agriculture (Public extension system) was assessed and data was presented in table 2 .

Table.1 Utility of extension methods $(n=75)$

\begin{tabular}{|c|c|c|c|c|c|c|c|c|}
\hline \multirow[t]{2}{*}{ S.No } & \multirow[t]{2}{*}{ Methods } & \multicolumn{2}{|c|}{ Frequent utility } & \multicolumn{2}{|c|}{ Sometimes } & \multicolumn{2}{|c|}{ Rarely } & \multirow[t]{2}{*}{ UI } \\
\hline & & No & $\%$ & No & $\%$ & No & $\%$ & \\
\hline $\mathbf{A}$ & \multicolumn{7}{|c|}{ INDIVIDUAL METHODS } & \\
\hline 1 & Farm and home visit & 66 & 88.00 & 9 & 12.00 & 0 & 0.00 & 288 \\
\hline 2 & Personal letter & 6 & 8.00 & 3 & 4.00 & 66 & 88.00 & 36 \\
\hline B & \multicolumn{7}{|l|}{ GROUP METHODS } & \\
\hline 3 & Demonstration & 51 & 68.00 & 24 & 32.00 & 0 & 0 & 268 \\
\hline 4 & Meetings & 75 & 100.00 & 0 & 0.00 & 0 & 0 & 300 \\
\hline 5 & Trainings & 72 & 96.00 & 3 & 4.00 & 0 & 0 & 296 \\
\hline 6 & Tours & 51 & 68.00 & 24 & 32.00 & 0 & 0 & 268 \\
\hline 7 & Farmers field school & 36 & 48.00 & 39 & 52.00 & 0 & 0 & 240 \\
\hline 8 & Field day & 30 & 40.00 & 45 & 60.00 & 0 & 0 & 224 \\
\hline $\mathbf{C}$ & \multicolumn{5}{|l|}{ MASS METHODS } & & & \\
\hline 9 & Leaflets & 72 & 96.00 & 3 & 4.00 & 0 & 0 & 296 \\
\hline 10 & Folder & 63 & 84.00 & 12 & 16.00 & 0 & 0 & 284 \\
\hline 11 & Booklet & 42 & 56.00 & 30 & 40.00 & 3 & 4.00 & 304 \\
\hline 12 & Radio & 0 & 0 & 27 & 36.00 & 48 & 64.00 & 136 \\
\hline 13 & Television & 0 & 0 & 18 & 24.00 & 57 & 76.00 & 124 \\
\hline 14 & Exhibition & 12 & 16.00 & 54 & 72.00 & 9 & 12.00 & 204 \\
\hline 15 & Wall/Tree posters & 6 & 8.00 & 54 & 72.00 & 15 & 20.00 & 188 \\
\hline
\end{tabular}




\begin{tabular}{|c|l|c|c|c|c|c|c|c|c|}
\hline $\mathbf{1 6}$ & $\begin{array}{l}\text { Hoardings/Flex } \\
\text { boards }\end{array}$ & 6 & 8.00 & 48 & 64.00 & 21 & 28.00 & 180 \\
\hline $\mathbf{D}$ & ICT TOOLS FOR TECHNOLOGY TRANSFER \\
\hline $\mathbf{1 7}$ & Portals & 9 & 12.00 & 48 & 64.00 & 18 & 24.00 & 188 \\
\hline $\mathbf{1 8}$ & Expert system & 0 & 0 & 51 & 68.00 & 24 & 32.00 & 168 \\
\hline $\mathbf{1 9}$ & Interactive CDs & 15 & 20.00 & 45 & 60.00 & 15 & 20.00 & 244 \\
\hline $\mathbf{2 0}$ & Websites & 0 & 0 & 12 & 16.00 & 63 & 84.00 & 108 \\
\hline $\mathbf{2 1}$ & e-mail & 6 & 8.00 & 12 & 16.00 & 57 & 76.00 & 132 \\
\hline $\mathbf{2 2}$ & Social networks & 6 & 8.00 & 48 & 64.00 & 21 & 28.00 & 180 \\
\hline $\mathbf{2 3}$ & Mobile services & 63 & 84.00 & 9 & 12.00 & 3 & 4.00 & 280 \\
\hline $\mathbf{2 4}$ & Video conferencing & 6 & 8.00 & 24 & 32.00 & 45 & 60.00 & 148 \\
\hline $\mathbf{2 5}$ & Tele conferencing & 6 & 8.00 & 27 & 36.00 & 42 & 56.00 & 144 \\
\hline $\mathbf{E}$ & PARTICIPATORY METHODS & & & & & & \\
\hline $\mathbf{2 6}$ & Brainstorming & 27 & 36.00 & 39 & 52.00 & 9 & 12.00 & 220 \\
\hline $\mathbf{2 7}$ & Focus group & 12 & 16.00 & 57 & 76.00 & 6 & 8.00 & 208 \\
\hline & discussion & 9 & 12.00 & 48 & 64.00 & 18 & 24.00 & 184 \\
\hline $\mathbf{2 8}$ & Participatory & & & & & & \\
\hline
\end{tabular}

Table.2 Relative effectiveness of extension methods $(n=75)$

\begin{tabular}{|c|c|c|c|c|c|c|c|c|c|c|}
\hline \multirow[t]{2}{*}{ S.No } & \multirow[t]{2}{*}{ Methods } & \multicolumn{2}{|c|}{$\begin{array}{c}\text { Very } \\
\text { effective }\end{array}$} & \multicolumn{2}{|c|}{ Effective } & \multicolumn{2}{|c|}{$\begin{array}{c}\text { Moderately } \\
\text { effective }\end{array}$} & \multicolumn{2}{|c|}{$\begin{array}{l}\text { Less } \\
\text { effective }\end{array}$} & \multirow[t]{2}{*}{ REI } \\
\hline & & No & $\%$ & No & $\%$ & No & $\%$ & No & $\%$ & \\
\hline $\mathbf{A}$ & \multicolumn{9}{|c|}{ INDIVIDUAL METHOD } & \\
\hline 1 & $\begin{array}{l}\text { Farm and home } \\
\text { visit }\end{array}$ & 57 & 76.00 & 5 & 7.00 & 13 & 17.00 & 0 & 0 & 328 \\
\hline 2 & Personal letter & 0 & 0 & 0 & 0 & 16 & 21.00 & 59 & 79.00 & 76 \\
\hline B & \multicolumn{9}{|c|}{ GROUP METHODS } & \\
\hline 3 & Demonstration & 51 & 68.00 & 18 & 24.00 & 0 & 0 & 6 & 8.00 & 348 \\
\hline 4 & Meetings & 54 & 72.00 & 21 & 28.00 & 0 & 0 & 0 & 0 & 372 \\
\hline 5 & Trainings & 42 & 56.00 & 33 & 44.00 & 0 & 0 & 0 & 0 & 356 \\
\hline 6 & Tours & 27 & 36.00 & 30 & 40.00 & 18 & 24.00 & 0 & 0 & 312 \\
\hline 7 & $\begin{array}{l}\text { Farmers field } \\
\text { school }\end{array}$ & 24 & 32.00 & 15 & 20.00 & 30 & 40.00 & 6 & 8.00 & 276 \\
\hline 8 & Field day & 3 & 4.00 & 18 & 24.00 & 48 & 64.00 & 6 & 8.00 & 224 \\
\hline $\mathbf{C}$ & \multicolumn{9}{|c|}{ MASS METHODS } & \\
\hline 9 & Leaflets & 60 & 80.00 & 6 & 8.00 & 9 & 12.00 & 0 & 0 & 332 \\
\hline 10 & Folder & 33 & 44.00 & 27 & 36.00 & 15 & 20.00 & 0 & 0 & 324 \\
\hline 11 & Booklet & 15 & 20.00 & 12 & 16.00 & 30 & 40.00 & 18 & 24.00 & 232 \\
\hline 12 & Radio & 0 & 0 & 0 & 0 & 15 & 20.00 & 60 & 80.00 & 120 \\
\hline 13 & Television & 0 & 0 & 3 & 4.00 & 12 & 16.00 & 60 & 80.00 & 124 \\
\hline 14 & Exhibition & 9 & 12.00 & 6 & 8.00 & 48 & 64.00 & 12 & 16.00 & 216 \\
\hline 15 & Wall/Tree posters & 0 & 0 & 6 & 8.00 & 48 & 64.00 & 21 & 28.00 & 180 \\
\hline
\end{tabular}




\begin{tabular}{|l|l|l|l|l|l|l|l|l|l|l|l|}
\hline $\mathbf{1 6}$ & $\begin{array}{l}\text { Hoardings/Flex } \\
\text { boards }\end{array}$ & 0 & 0 & 6 & 8.00 & 51 & 68.00 & 18 & 24.00 & 184 \\
\hline $\mathbf{D}$ & \multicolumn{7}{|c|}{ ICT TOOLS FOR TECHNOLOGY TRANSFER } \\
\hline $\mathbf{1 7}$ & Portals & 0 & 0 & 0 & 0 & 45 & 60.00 & 30 & 40.00 & 160 \\
\hline $\mathbf{1 8}$ & Expert system & 0 & 0 & 3 & 4.00 & 24 & 32.00 & 48 & 64.00 & 132 \\
\hline $\mathbf{1 9}$ & Interactive CDs & 0 & 0 & 0 & 0 & 42 & 56.00 & 33 & 44.00 & 116 \\
\hline $\mathbf{2 0}$ & Websites & 0 & 0 & 0 & 0 & 12 & 16.00 & 63 & 84.00 & 108 \\
\hline $\mathbf{2 1}$ & e-mail & 0 & 0 & 0 & 0 & 6 & 8.00 & 69 & 92.00 & 108 \\
\hline $\mathbf{2 2}$ & Social networks & 0 & 0 & 0 & 0 & 12 & 16.00 & 63 & 84.00 & 100 \\
\hline $\mathbf{2 3}$ & Mobile services & 39 & 52.00 & 21 & 28.00 & 12 & 16.00 & 3 & 4.00 & 328 \\
\hline $\mathbf{2 4}$ & Video conferencing & 0 & 0 & 0 & 0 & 0 & 0 & 75 & 100.00 & 100 \\
\hline $\mathbf{2 5}$ & Tele conferencing & 0 & 0 & 0 & 0 & 3 & 4.00 & 69 & 92.00 & 96 \\
\hline $\mathbf{E}$ & & & PARTICIPATORY METHODS & & & \\
\hline $\mathbf{2 6}$ & Brainstorming & 0 & 0 & 24 & 32.00 & 45 & 60.00 & 6 & 8.00 & 196 \\
\hline $\mathbf{2 7}$ & Focus group & 3 & 4.00 & 15 & 20.00 & 48 & 64.00 & 9 & 12.00 & 212 \\
\hline & discussion & & & & & & & & & \\
\hline $\mathbf{2 8}$ & Participatory & 3 & 4.00 & 3 & 4.00 & 42 & 56.00 & 27 & 36.00 & 172 \\
& workshop & & & & & & & & & \\
\hline
\end{tabular}

Table.3 Contribution of Selected Independent Variables towards the Relative Effectiveness of the Extension Methods Employed by the Extension officials in Public Extension System

\begin{tabular}{|c|c|c|c|c|}
\hline $\begin{array}{l}\text { Variable } \\
\text { Number }\end{array}$ & Independent Variable & $\begin{array}{c}\text { Partial } \\
\text { Regression } \\
\text { Coefficient }\end{array}$ & $\begin{array}{l}\text { Standard } \\
\text { Error of } \\
\text { Regression }\end{array}$ & $\begin{array}{l}\text { Computed } \\
\text { 't' value }\end{array}$ \\
\hline $\mathbf{X}_{1}$ & Educational Qualification & 2.036 & 1.151 & 1.769 \\
\hline $\mathbf{X}_{2}$ & Organisational Support & -0.498 & 0.509 & -0.978 \\
\hline $\mathbf{X}_{3}$ & $\begin{array}{l}\text { Perception towards conventional } \\
\text { extension methods }\end{array}$ & 0.272 & 0.760 & 0.357 \\
\hline$X_{14}$ & $\begin{array}{l}\text { Skill in employing Extension } \\
\text { Methods }\end{array}$ & -1.047 & 1.799 & -0.582 \\
\hline $\mathbf{X}_{5}$ & $\begin{array}{l}\text { Skills in choosing appropriate } \\
\text { Extension methods }\end{array}$ & 6.673 & 2.493 & $2.676^{*}$ \\
\hline $\mathbf{X}_{6}$ & $\begin{array}{l}\text { Provision of Vehicles to employ } \\
\text { extension methods }\end{array}$ & -1.165 & 2.658 & -0.438 \\
\hline $\mathbf{X}_{7}$ & $\begin{array}{l}\text { Experience in employing extension } \\
\text { methods }\end{array}$ & 5.276 & 2.116 & $2.494 *$ \\
\hline $\mathbf{X}_{8}$ & $\begin{array}{l}\text { Inherent attitude/interest } \\
\text { employing extension methods }\end{array}$ & -0.914 & 2.234 & -0.409 \\
\hline$X_{9}$ & $\begin{array}{l}\text { Credibility possessed by farmers on } \\
\text { extension workers }\end{array}$ & -8.414 & 2.903 & $-2.898^{*}$ \\
\hline $\mathbf{X}_{10}$ & Recruitment of required man power & 1.713 & 2.355 & 0.727 \\
\hline$X_{11}$ & Perception towards ICT & -0.631 & 1.622 & -0.389 \\
\hline
\end{tabular}




\section{Effectiveness of Individual method}

The data pertaining to individual method revealed that majority of extension officials (76 per cent) perceived farm and home visits as very effective among the individual methods and the relative effectiveness index for this method was worked out to be 328 . In continuation of the discussion related to utilization of personal letter in table 1, the relative effectiveness was also found to be low for personal letter with REI of 76.

\section{Effectiveness of Group methods}

Among the group methods, three methods were found to be relatively effective as perceived by extension officials. Meetings (72 per cent \& 28 per cent), Demonstrations (68 per cent $\& 24$ per cent) and Trainings (56 per cent \& 44 per cent) were the group methods rated to be very effective to effective by extension officials with REI of 372,356 and 348 respectively.

The order of the effectiveness of the extension methods 'tours' as perceived by extension officials was effective (40 percent) very effective (36 percent) and moderately effective (24 per cent) with REI of 312. This was followed by Farmer Field School (40 per cent $\& 20$ per cent) and field day (64 per cent \& 24 per cent) which were rated to be moderately effective to effective with REI of $276 \& 224$ respectively. Meetings, Trainings $\&$ Demonstrations were part of the regular Extension Programmes and hence the extension officials perceived them to be effective. Tour and farmer field school were being performed as part of ATMA, NFSM and pulse village scheme. The extension officials told that "seeing is believing" and experiencing were the important reasons for these methods to be perceived as effective ones.

\section{Effectiveness of Mass methods}

Among the mass methods, leaflets and folders were perceived to be very effective $(80$ per cent) and very effective and effective (44 per cent and 36 per cent) respectively. The REI for leaflet and folder were 332 and 324 respectively. The response for booklet was mixed as considerable number of extension officials perceived this method to be moderately effective (40 per cent), very effective ( 20 per cent), effective (16 per cent) and less effective( 24 per cent) with REI of 232. The exhibition was perceived to be moderately effective (64 per cent) with REI of 216. As discussed in utility of extension methods, radio ( 80 per cent) and television (80 per cent) were perceived to be less effective by majority of extension officials with REI of 120 and 124 respectively.

Majority of extension officials felt that wall/tree posters (64 per cent and 28 per cent), Hoardings/Flex boards (68 per cent and 24 per cent) as moderately effective to less effective with REI of 180 and 184 respectively. This was in line with the findings about their utility in table 1 . Leaflets and folders were being produced for several extension programmes organized by department of agriculture and extension officials felt that the circulation of them is really increased the awareness of the technologies. For example, leaflets produced on SRI cultivation in paddy have received much attention among the farmers. Though radio and television programmes could bring behavioral changes among farmers they were not utilized properly and hence extension officials felt them to be ineffective.

\section{Effectiveness of ICT tools}

Among the ICT tools for technology transfer, mobile service was found to be very effective (52 per cent) to effective (48 per cent) with 
REI of 328. All the other ICT tools were perceived to be moderately effective to less effective. Portals, expert system and interactive CDs were found to be somewhat effective as they were being utilized by the extension officials rarely. Websites, e-mail, Social networks, Video conferencing and teleconferencing were perceived to be less effective as most of the officials, though used them for personal purposes did not make use of them for technology delivery.

\section{Effectiveness of Participatory methods}

All the three participatory methods were perceived to be moderately effective to effective. Among the three, focus group discussions were perceived to be effective followed by brainstorming and participatory workshops with REI of 212, 196, 172 respectively. The extension officials reported that despite they were aware of participatory approaches they did not have skill in organising it and hence perceived them to be moderately effective.

\section{Contribution of Selected Independent Variables towards the Relative Effectiveness of the Extension Methods Employed by the Extension officials in Public Extension System}

To find out the contribution of selected independent variables which were presumed to predict the Relative Effectiveness of the Extension Methods employed by the Extension Officials of Public Extension System, Multiple Regression analysis was carried out using SPSS 21.0 version.

The scores obtained by each of the Extension Method for their perceived effectiveness by individual Extension official in Public Extension System was summated. The summated score for all the selected respondents was worked out and the column containing the summated scores will be continuous in nature. This Relative effectiveness scores was taken as dependent variable and predicted using eleven of the predictor variables through Multiple Regression analysis. The independent or predictor variables were chosen based on nature of private extension system and their appropriateness and relevancy in predicting the effectiveness of extension methods effectively. The results of the Multiple Regression analysis was presented in table 3.

Results indicated that the $\mathrm{R}^{2}$ value was 0.687 which indicated that 68.70 per cent variation in Relative Effectiveness of Extension methods was explained by selected 11 independent variables. The ' $F$ ' value indicated that the analysis was significant at one per cent level of probability. Therefore the prediction equation was fitted for Relative Effectiveness of Extension methods which is given below.

$\mathrm{Y}_{1}=41.457+2.036 \mathrm{X}_{1}-0.498 \mathrm{X}_{2} 0.272 \mathrm{X}_{3}-$ $1.047 \mathrm{X}_{4}+6.673 \mathrm{X}_{5}-1.165 \mathrm{X}_{6}+5.276 \mathrm{X}_{7} \quad-$ $0.914 \mathrm{X}_{8}-8.414 \mathrm{X}_{9}+1.713 \mathrm{X}_{10}-0.631 \mathrm{X}_{11}$

Among the twelve variables selected, three variables were found to be significantly contributing to the effectiveness of extension methods employed. Among the three, two were positively contributing and one were negatively contributing to the dependent variable.

Variables namely Skill in choosing appropriate extension methods $\left(\mathrm{X}_{5}\right)$ and experience in employing extension methods $\left(\mathrm{X}_{7}\right)$ were found to be positive and significantly contributing towards the Relative Effectiveness of Extension methods in Public Extension system at five per cent level of probability. The variable credibility possessed by farmers on extension workers $\left(\mathrm{X}_{9}\right)$ were found to be negative and 
significantly contributing towards the Relative Effectiveness of Extension methods in Public Extension system at five per cent level of probability. The strength of contribution of these variables could be explained as one unit increase certeris paribus in skill in choosing appropriate extension methods and year of experience in employing extension methods would bring an increase of 6.673 and 5.278 units in Relative Effectiveness of Extension methods in Public Extension system respectively.

Further, it could be interpreted as one unit increase certeris paribus in credibility possessed by farmers on extension workers would decrease 8.414 units in Relative Effectiveness of Extension methods in Public Extension system. The experience in employing extension methods over a period of time would have enhanced the skill.

The Extension officials in Public Extension system were found to employ group based methods like meetings, trainings and demonstrations etc., predominantly. Further, the Extension officials are permanent workers in the Government system who put in significant years of service in the system might have gained experience and skill and thus contributed to the effectiveness of the extension methods employed.

The credibility of farmers on the extension worker has already been reported elsewhere in this report as a moderately influencing factor for employing extension methods by the extension officials of public extension system.

The credibility gap would always result in reduced effectiveness, since the farmers need to believe the person who is teaching him. Hence the negative contribution of this variable was justified.

\section{Recommendations from the study}

One major finding from the study was that the Extension officials of public extension system though well versed with recent ICT gadgets were not using them for technology transfer. Hence, the Extension personnel of public extension system are to be given training on utility of advanced ICT tools like expert system and utility of portals

The effectiveness of the group methods was found to be high in public extension system, whereas the participatory methods were found to be least utilized and least effective. Participatory methods hold the key of success of Extension Programme as it ensures the participation of clientele in the programme which will have a multiplier effect of diffusing the content of the programme to more number of farmers. Further, the ATMA guidelines warrants the Extension Officials to be proficient in employing PRA tools for drawing up Strategic Research and Extension Plan (SREP) for blocks. Hence, the officials of Public Extension system needs to be sensitized about participatory extension methods through capacity building on participatory methods

It could be seen from the findings, that radio and television did have a moderate effectiveness only. This being so, in recent years the relevance of community radio which is delivering location specific information has been increasing. Hence, the Extension Administrators in Department of Agriculture may think of employing the concept of Community Radio wherever it is possible and feasible.

Yet another important finding is the relevance of skill and experience in utility of Extension methods did have a say in the effectiveness of Extension Methods. 
Hence, it is high time that exclusive training programmes for utility of conventional and modern Extension Methods on regular basis by competent resource persons are to be organized for Extension personnel of Department of Agriculture. Agricultural Production Commissioner of the State may come up with a policy to integrate this training into the budget and activity of Department of Agriculture.

\section{References}

Khan, Ayesha and Muhammad Akram, 2012. "Farmers Perception of Extension Methods Used by Extension Personnel for Dissemination of New Agricultural Technologies In Khyber Pakhtunkhwa: $\quad$ Pakistan." Sarhad Journal of Agriculture, vol. 28, no. 3, 2012.

Baral, P., R. Paudel, B.B. Adhikari, M. Sudedi and M. Jaishi, 2018. Effectiveness of Extension Methods: A Case of Western Mid-Hills in Nepal, J. Inst. Agric. Anim. Sci. 35:
49

Jonna Luukkainen, 2012, A Comparison of Extension Methods Used by Different Agricultural Extension Service Providers in Nyandarua County, Kenya, Bachelor thesis submitted to University of Applied Sciences, Kenya

Hung Gia Hoang, 2018. "Effectiveness of Extension Program Delivery Methods as Perceived by the Central Vietnamese Extension Workers" American Journal of Rural Development. 2018, 6(2), 45-48. DOI: 10.12691/ajrd-6-2-3

Singh, K., Meena, M S and Swanson, Burton, 2013. Extension in India by Public Sector Institutions: An Overview. SSRN Electronic Journal. 10.2139/ssrn.2315457.

Kamalpreet Kaur and Prabhjot Kaur. 2018. Agricultural Extension Approaches to Enhance the Knowledge of Farmers. Int.J.Curr.Microbiol.App.Sci. 7(02): 2367-2376.

\section{How to cite this article:}

Poovarasan, N., M. Ramasubramanian, M. Senthil Kumar and Anuratha, A. 2020. An Analysis of Utility and Effectiveness of Extension Methods Employed by the Extension Personnel of Public Extension System in Southern Tamil Nadu. Int.J.Curr.Microbiol.App.Sci. 9(12): 15261537. doi: https://doi.org/10.20546/ijcmas.2020.912.181 